feet altitude, and maintained at that height until it was necessary to put it into a slow descent. This occurred over Bedford, one of the few towns that the pilot had been able to see through the clouds. He reported that he had been perfectly comfortable and warm, had had no occasion to use oxygen, and had no feeling of fatigue. The cockpit of this type of machine is entirely covered over with transparent cellulose material, and attention is paid to keeping the pilot warm.

\section{Film illustrating Movement of a Fœtus}

AT the meeting of the Royal Society held on February 10, Sir Joseph Barcroft and D. H. Barron showed a film illustrating the development of movement in the foetus of the sheep. The development of movement was depicted in respect of : $(a)$ the types of movement which appear at different fotal ages, and $(b)$ the individuation of certain sorts of purposive movement from a general mass movement. The period of gestation is about 145 days. Up to about 35 days, the foetus is immobile (type 1). At 35 days it commences to exhibit movements which are always 'jerky' (type 2). At 47-50 days it is almost incessant motion, which is 'sustained' (type 3). After 50 days the fotus becomes quiescent (type 4). The following analysis may be made of these types: If the spinal cord be cut just below the brain at 60 days, without taking the fotus out of the uterus, and the fotus be allowed to continue growing until the cut fibres have degenerated, its body will exhibit jerky movements (type 2), whilst its head is quiescent (type 2). If the central nervous system is transected below the pons, the whole fœetus exhibits jerky movements (type 4). If the central nervous system is sectioned above the red nucleus the foetus exhibits sustained movements (type 3). The mechanism for the integration of 'jerky' into 'sustained' movements is in the region of the red nucleus, and the mechanism for the inhibition of movement is preponderantly above that. Later parts of the film showed the development of respiratory movements (especially in relation to somatic movement), the development of progressive movement and the development of 'righting' movements.

\section{Development of Calcutta}

“The Second City of the Empire", compiled by Dr. P. C. Bagchi, has been published under the auspices of the Indian Science Congress Association as guide book and souvenir of its silver jubilee meeting recently held in Calcutta. The brochure, which is fully illustrated, gives a historical account of the rise and growth of this eity and describes the develop. ment of its municipal administration, educational, industrial, public and social services. Calcutta came into existence towards the end of the seventeenth century, and largely owing to its geographical position rapidly grew into an important town. According to the 1935 census, its population now numbers more than a million. The city is mainly industrial and commercial, textiles and tea being two of the chief commodities with which it is concerned. Rapid strides have been made in education during the last century, particularly since the foundation of the University in 1857. To illustrate the more modern developments on the medical side, mention may be made of the opening of the Pasteur Institute in 1924, and more recently still, the Institute of Hygiene and Public Health. The formation of the Vangiya Sahitya Parishad in 1894, for the cultivation and improvement of the Bengali language and literature, has done much to further the study of arts, while the Bose Research Institute, opened in 1917, is an example of the interest taken in pure scientific research.

\section{The Volta Temple at Como}

IN Engineering of January 7 and 21 and February 4, Mr. F. Walker gives an account of the beautiful Volta Temple at Como, erected as a permanent memorial. The erection of the Temple was made possible by the generosity of $\mathrm{Gr}$. Uff. ou Francesco Somaini, whose commission to the architect Signor Federico Frigerio placed no limits whatsoever on the class of work or expenditure involved. Standing in the public gardens near the edge of a lake in Como, the Temple is a white marble building in the NeoClassical style, measuring approximately $25 \mathrm{~m}$. in length, $20 \mathrm{~m}$. in depth and $21 \mathrm{~m}$. in height. The main building consists of a large circular hall surmounted by a dome, which is supported by four corner pilasters and eight marble columns. Above the capitals of the pillars is a cornice bearing in gold letters an inscription of dedication. A marble staircase leads to a mezzanuil gallery around the central rotunda, and on the parapet of the gallery are four sculptured panels illustrating incidents in Volta's life. One of these represents him demonstrating his pile to Napoleon at Paris. Though much of Volta's apparatus was destroyed in the fire at the Como Exhibition of 1899, his manuscripts and books were saved and replicas of his apparatus are shown in cases, together with many personal relics. The entire expense for the collection of apparatus has been borne by Signor Somaini, who has further endowed the Temple with a capital of 500,000 lire, the interest of which is to provide scholarships. $\mathrm{Mr}$. Walker's article is accompanied with many photographs of what appears to be the most remarkable monument to any man of science.

\section{Early Hittite Civilization in Cilicia}

REsults, which at first sight hold out great promise of additions to knowledge of the early stages in the extension of Hittite culture, have been obtained by the Neilson Expedition of the University of I iverpool under Prof. J. Garstang, now engaged in excavating an archæological site near Mersina on the Cilician coast of Asia Minor. A double-walled fortress has been discovered, which is thought to mark the site of a frontier post between the rival southern kingdom of Assawa and the allied State of Kizzuwadna (which seems to have included Tarsus) during the sixteenth or fifteenth century B.C., when the latter stage formed part of the realm of the Hatti, usually identified under the more familiar name of Hittites. According to a report of recent excavations (The Times, February 9), deep soundings on a con- 